\title{
Comparison of Ziehl - Neelsen (ZN) Staining and Fluorescent (FL) Staining in Suspected Cases of Tuberculosis
}

\author{
Rekha Bhandari ${ }^{1}$, Dushyant Singh Gaur ${ }^{1 *}$, Aarti Kotwal ${ }^{2}$ and Anuradha Kusum ${ }^{1}$ \\ ${ }^{1}$ Department of Pathology, Swami Rama Himalayan University, India \\ ${ }^{2}$ Department of Microbiology, Swami Rama Himalayan University, India
}

*Corresponding author: Dr. Dushyant Singh Gaur, Professor, Department of Pathology, HIMS, Swami Rama Himalayan University, Jollygrant, Dehradun, Uttarakhand, 248140, India, Tel: +91-98370-20745

\begin{abstract}
Introduction: Early diagnosis of tuberculosis is important for therapeutic reasons and to control the spread of infection $[1,2]$. Culture of $M$. tuberculosis is the gold standard method for the diagnosis of TB [3]. However, culture is a slow process requiring specialized laboratories and skilled staff. Hence there is a need for a rapid, cheaper and effective technique for the detection of the tubercle bacilli.

Material and methods: A total of 200 clinically suspected cases of tuberculosis were included in the study. All the cytological specimens procured were smeared and stained for both $\mathrm{ZN}$ and $\mathrm{FL}$ staining. A part of the sample was used for Lowenstein Jensen (LJ) culture. Patients on ATT were excluded from the study.

Results: The maximum cases were in the age group of 2130 years. In $57 \%$ cases, patients were male with M:F ratio of 1.3:1. The sensitivity of FL $(95.83 \%)$ was more as compared to $\mathrm{ZN}(91.67 \%)$. The difference in the case detection rate was statistically significant with $p$ value 0.001 . The average time taken to screen per slide by ZN was more ( 4.32 mins) as compared to that by $\mathrm{FL}(2.28$ mins), reflecting a time saving by $47 \%$.

Conclusion: FL staining has an upper edge in respect to efficacy, time saving and less observer fatigue. Hence replacement of the age old $\mathrm{ZN}$ technique and using $\mathrm{FL}$ microscopy may be considered as alternative for diagnosis of tuberculosis.
\end{abstract}

\section{Keywords}

Ziehl-Neelsen, Fluorescent, Tuberculosis, Culture

\section{Introduction}

As per the World Health Organization (WHO), tubercular infections are presently spreading at the rate of one person per second per million people, with three millions dying from it [1]. Early diagnosis of tuberculosis is important for therapeutic reasons and to control the spread of infection [2]. Culture of $M$. tuberculosis is the gold standard method for the diagnosis of TB [3]. However, culture is a slow process requiring specialized laboratories and highly skilled staff. In developing countries like India with a high tuberculosis burden and limited number of adequate resources and infrastructure, the diagnosis of Tuberculosis relies mostly on smear microscopy for Acid Fast Bacilli (AFB), however its sensitivity is considered to be low in paucibacillary cases [4].

Although several research groups have investigated the clinical validity and differences in efficacy of various staining methods, the technical and procedural factors can influence the sensitivity of each staining technique. Moreover, very little previous literature related to the comparison of Auramine-o stained smears under fluorescent microscopy with ZN stain for detection of tubercle bacilli in cytological specimens is available till date.

Hence, in view of above perspective, the present comparative study has been designed to assess the efficacy of Ziehl-Neelsen staining method versus fluorescent staining in the detection of mycobacterium 
from various cytological specimens of suspected cases of tuberculosis.

\section{Material and Methods}

The study was conducted in the Cytology unit of Department of Pathology in collaboration with Department of Microbiology over a period of 12 months after obtaining approval from the institutional ethical committee.

\section{Inclusion criteria}

A total of 200 consecutive suspected cases of tuberculosis were included in the study.

FNAC of lymph node, irrespective of age and gender with suspicious clinical history or radiological evidence were included in the study along with other body fluids.

\section{Exclusion criteria}

Pre-diagnosed cases already on anti-tubercular therapy.

Ziehl-Neelsen and Auramine-o staining (Sigma-
Aldrich) was done as per Standard Operating Protocol. Grading of the smears was done as per the RNTCP guidelines. Culture on L-J media was done to compare the two staining procedures.

Interpretation and analysis of obtained results was carried out using software SPSS version 20 and appropriate statistical test were employed.

\section{Results}

In the present study, $57 \%$ cases $(n=114)$ were males and $43 \%(n=86)$ were females with male to female ratio of 1.3:1. Maximum number of cases ( $n=52 / 200 ; 26 \%$ ) were in the age group of 21-30 years (Figure 1 ).

The most common presenting complaint of the cases was fever $(n=177 / 200 ; 88.5 \%)$ followed by malaise ( $n$ $=115 ; 57.5 \%)$ and cough $(n=109 ; 54.5 \%)$. Maximum number of cases were lymph node aspirates ( $n=79$; $39.5 \%)$ followed by pleural fluid ( $n=45 ; 22.5 \%)$ and pus ( $n=44 ; 22 \%)$. There was one case each of Endotracheal tube secretions and Trans Bronchial Needle Aspiration.

Cervical lymph node was the most frequently

No. of Cases

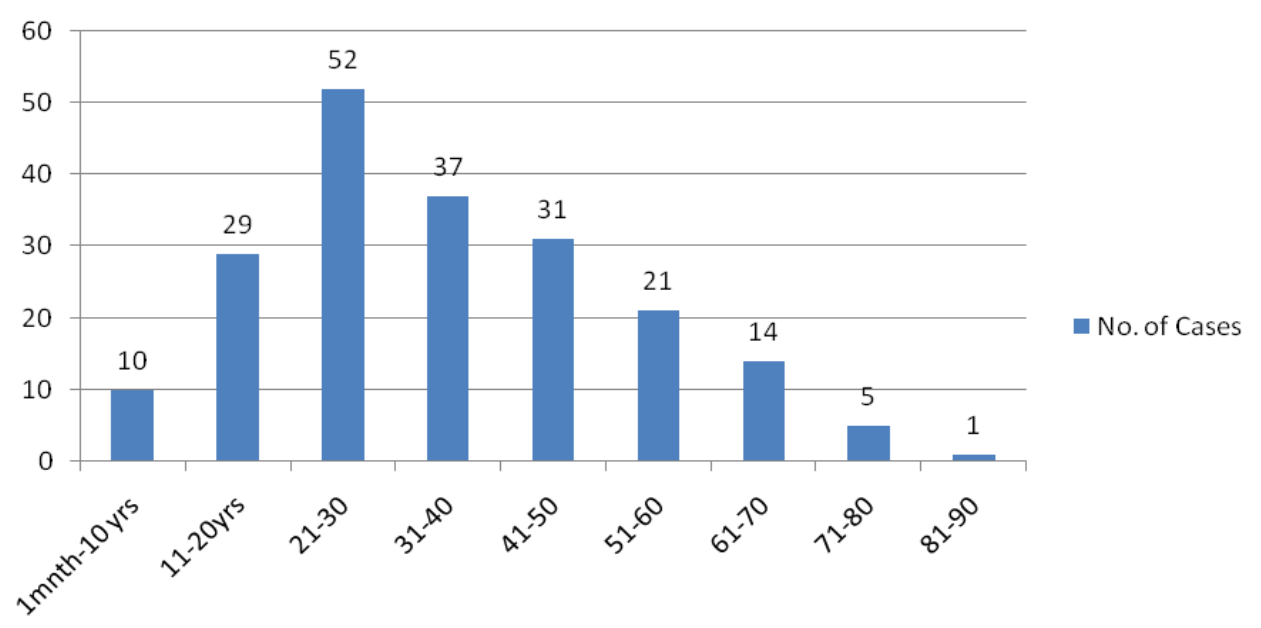

Figure 1: Distribution of cases according to age $(n=200)$.
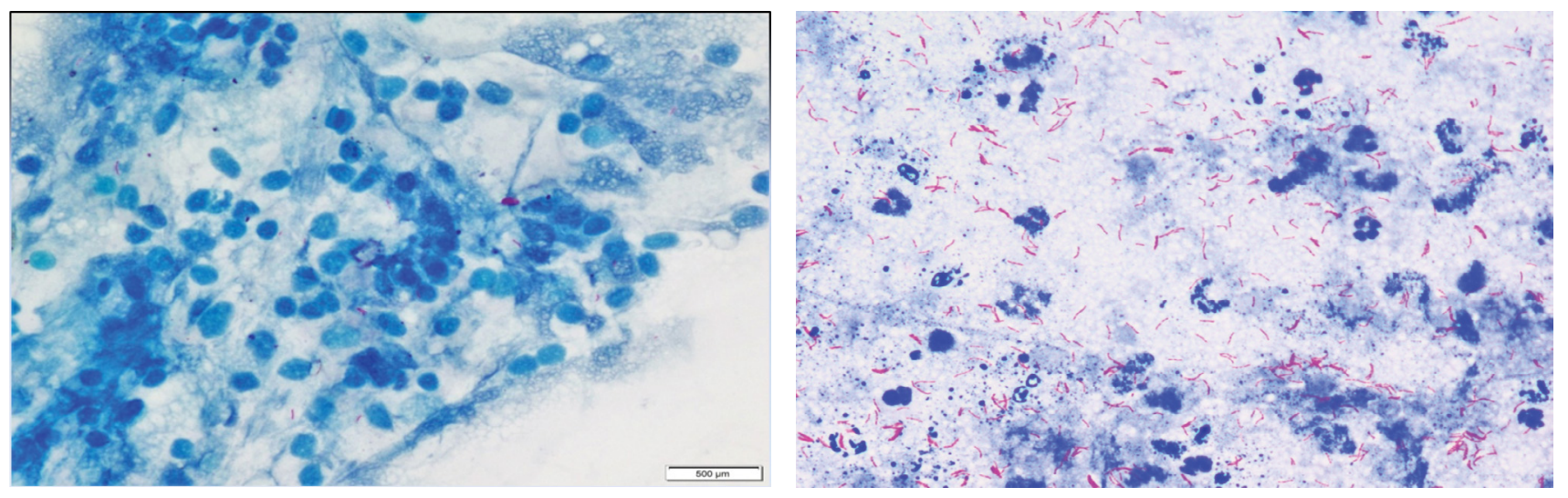

Figure 2: (A) Paucibacillary case on ZN staining at 100x (oil immersion view; (B) Multibacillary case on ZN staining at $100 x$ (oil immersion view). 

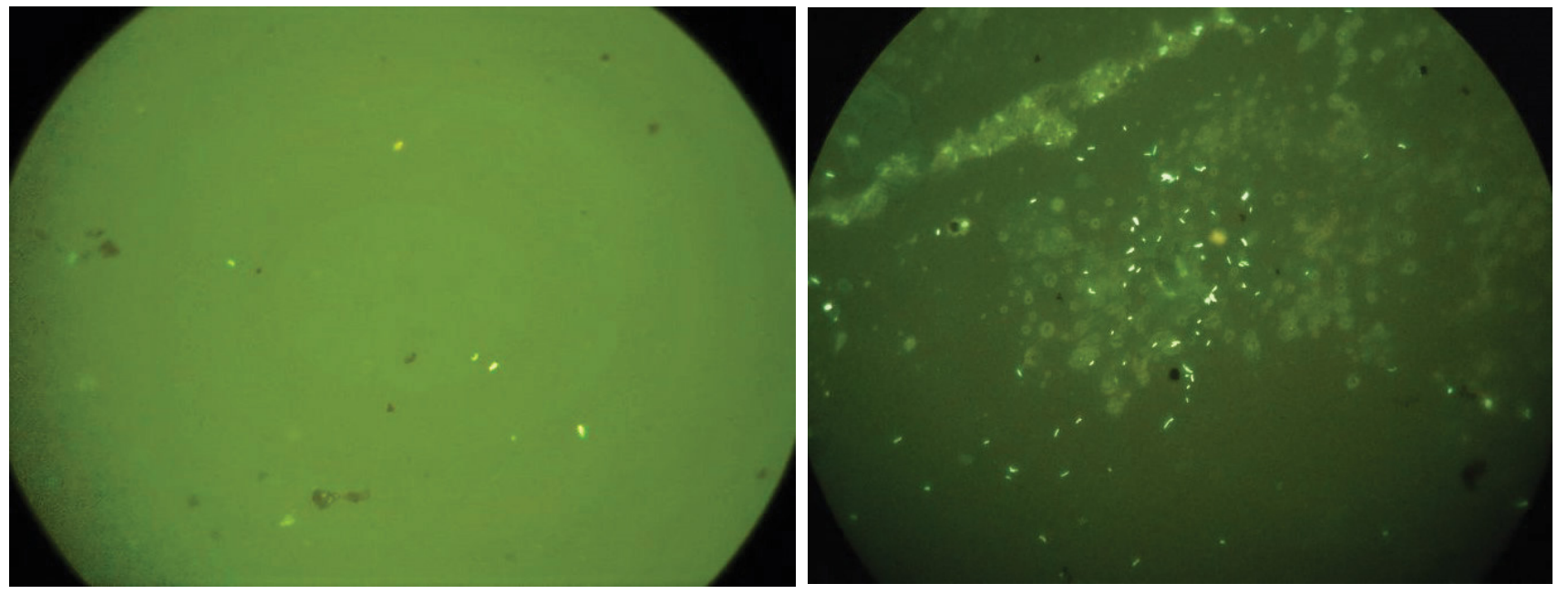

Figure 3: (A) Paucibacillary case on FL staining at 40x (high power view); (B) Multibacillary case on FL staining at 40x (high power view).

Table 1: Test results.

\begin{tabular}{|l|l|l|}
\hline & ZN & FL \\
\hline True Positive & 22 & 23 \\
\hline True Negative & 175 & 174 \\
\hline False Positive & 01 & 02 \\
\hline False Negative & 02 & 01 \\
\hline
\end{tabular}

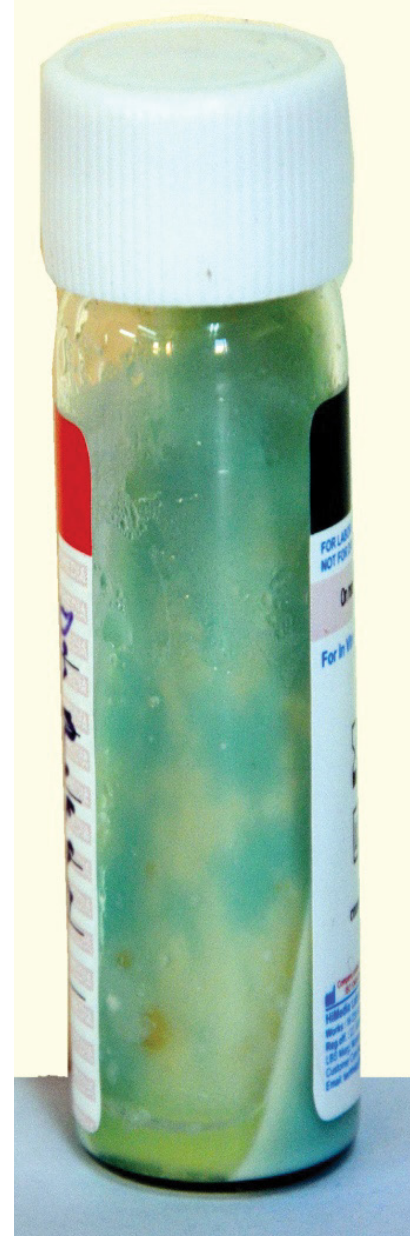

Figure 4: Lowenstein-Jensen medium slant showing buff coloured and rough colonies of the tubercle bacilli. aspirated lymph node ( $\mathrm{n}=71 ; 71 \%$ ) followed by supraclavicular lymph node $(n=11 ; 11 \%)$. The maximum number of positive cases was seen in Cervical lymph node ( $n=13$ ), followed by two cases each of breast lump and vertebral aspirate.

Of the 200 samples processed, a total of 25 cases were positive either on ZN (Figure 2) or FL (Figure 3), majority of the cases $(92 \%, n=23)$ were paucibacillary. The multibacillary cases were diagnosed equally by both the staining methods, however the only true positive case diagnosed in addition on FL was paucibacillary (Table 1).

The isolation rate by $L$ culture was $12 \%(24 / 200)$ (Figure 4). The difference in case detection rates by ZN and $F L$ is statistically significant with $p$-value 0.001 by Z-test.

\section{Discussion}

Smear microscopy remains the crux for diagnosis of TB. However, the search for rapid and efficient staining methods continues.

In our study, the smear positivity rate of $\mathrm{AO}$ stained smears $(12.5 \%)$ were better than $\mathrm{ZN}$ stained smears (11.5\%) (Table 2).

The findings were comparable with those observed by Golia S, et al. [5], Suria J, et al. [6] and Ulukanligil, et al. [7] where the smear positivity rates by ZN were $10.41 \%, 12.4 \%, 9.89 \%$ and $\mathrm{FL}$ were $16.56 \%, 19.1 \%$, $12.47 \%$ respectively.

In the present study, fluorescent microscopy detected additional two positive cases which would have been missed by ZN microscopy alone. However one of them turned out to be negative on culture reflecting either a false positive result or might be an outcome of harsh decontamination of the sample accounting to loss of the viable bacilli [8]. 
Table 2: Comparison of ZN \& FL stain.

\begin{tabular}{|l|l|l|}
\hline & ZN & FL \\
\hline Sensitivity $=\frac{T P}{T P+F N}$ & $91.67 \%$ & $95.83 \%$ \\
\hline Specificity $=\frac{T P}{T P+F N}$ & $99.43 \%$ & $98.86 \%$ \\
\hline Positive Predictive Value (PPV) $=\frac{T P}{T P+F N}$ & $95.65 \%$ & $92 \%$ \\
\hline Negative Predictive Value (NPV) $=\frac{T P}{T P+F N}$ & $98.87 \%$ & $99.43 \%$ \\
\hline Smear Positivity & $(23 / 200)=11.5 \%$ & $(25 / 200)=12.5 \%$ \\
\hline Accuracy & $98.5 \%$ & $98.5 \%$ \\
\hline Average Time Taken/Slide & $4.32 \mathrm{mins}$ & $2.28 \mathrm{mins}$ \\
\hline
\end{tabular}

TP: True Positive; TN: True Negative; FP: False Positve; FP: False Negative.

Table 3: Efficacy of ZN \& FL in case detection.

\begin{tabular}{|l|l|l|}
\hline & $\begin{array}{l}\text { Disease Positive } \\
\text { (Culture Positive) }\end{array}$ & $\begin{array}{l}\text { Disease Negative } \\
\text { (Culture Negative) }\end{array}$ \\
\hline ZN Positive & 22 & 01 \\
\hline FL Positive & 23 & 02 \\
\hline
\end{tabular}

The major strength of our study was comparing the staining methods with culture which is considered as Gold standard for the diagnosis of mycobacterial infection. The sensitivity and specificity of both the staining methods was calculated by comparing the culture results, which adds to the strength to the evidence to the values.

Large number of studies showed that sensitivity of ZN ranged from $32 \%$ to $94 \%$ and fluorescence microscopy was on average $10 \%$ more sensitive than ZN [9].

In the present study, sensitivity of ZN came out to be $91.67 \%$ as compared to $95.83 \%$ of FL (Table 2). Similar results were obtained by SJ Murray, et al. (93\% by FL and $73 \%$ by ZN ) [10], K Prashanthi, et al. (69\% by FL and $50 \%$ by ZN) [11], A Jain, et al. ( $41 \%$ by FL and $32 \%$ by $Z N$ ) [12], Githui, et al. ( $80 \%$ by FL and $65 \%$ by ZN staining) [13] and Ulukanligil, et al. $(85.2 \%$ by $F L$ and $67.6 \%$ by ZN ) [7].

It may be because organisms in FL stain offer better contrast, appearing as brilliant yellow against a dark background. The use of this staining even by some colour blind investigator can be an additional advantage of this technique.

Lower specificity of FL microscopy compared with conventional light microscopy has been reported previously [14]. In the present study, the specificity of FL microscopy (98.86\%) was slightly lower than that of ZN microscopy (99.43\%) (Table 2). Scanty AFB results on FL microscopy were less likely to be associated with a positive culture result. It is thus more likely that mycobacteria from paucibacillary specimens were killed during decontamination process and failed to grow in culture [8].
False positivity of ZN microscopy and FL fluorescent microscopy is $0.5 \%(1 / 200)$ and $1.0 \%(2 / 200)$ respectively, reported in our study which is not significant. The reasons for false positivity may be specimen from patients on anti-tubercular treatment or processing a bloody sample [15]. The ZN method is also known to give occasional false positive results [16], probably because of the heating step involved in it [17].

In the present study the statistical difference between case detection rates by the two stains was statistically significant ( $p$ value $<0.05$ ) (Table 3 ).

This was in concordance with studies done in India by Mistry Y, et al. [18], Jain A, et al. [12], Dagar V, et al. [19] as well as abroad by Zailani SB, et al. [20] and Zaib-unNisa, et al. [21] where all of them reported a statistically significant difference between case detection by the two staining techniques.

However findings by Subramani $P$, et al. [22] was in discordance with the present study stating no significant difference between results of the two staining methods.

The sensitivity of smear microscopy is largely determined by the duration of microscopic examination [1]. In high work load settings, the amount of time spent on examining each smear by conventional $\mathrm{ZN}$ is low which would probably compromise the sensitivity.

The advantage of fluorescence microscopy is the possibility to scan a smear at 400x magnification rather than at $1000 x$ magnification, allowing theoretical reduction of examination time of the same area to one sixteenth as the surface increases by the square of the diameter. Practically the examination time is reduced to about 10 fold with Fluorescent compared to bright-field microscopy using a 3-fold different [23] magnification (400x vs. $1000 x)$.

In the present study the average time taken to screen per slide by ZN was more (4.32 mins) as compared to that by $\mathrm{AO}$ ( 2.28 mins), reflecting a time saving by $47 \%$ (Table 2). 
In a study by Tiwari, et al. [24] the mean reading time of Auramine $\mathrm{O}$ technique was three times faster than the ZN technique with very good acceptance by the technicians. This was similar to the observation by Marais BJ, et al. [25], where he observed 1.4 minutes to process a slide by FM as compared to 3.6 minutes with conventional ZN microscopy, reflecting a time saving of $61 \%$ with FM. Since it is less time consuming hence more slides can be processed in a shorter duration of time.

Despite the fact that conventional fluorescent microscopy has documented higher sensitivity than ZN in huge number of studies and has tremendous potential to reduce laboratory workloads [26], still its incorporation in routine practice has been hampered by various factors including complexity of the microscope, need for a dark room and perceived health risks associated with ultraviolet light exposure [27].

\section{Conclusion}

Our findings indicate that FL staining techniques is more effective as far as diagnosis of the disease is concerned, particularly in paucibacillary cases. Taking other factors into account, FL staining has an upper edge in respect to time saving and less observer fatigue. Hence replacement of the age old ZN technique by using FL microscopy may be considered as alternative for diagnosis of tuberculosis after conducting large scale feasibility studies in Indian settings.

Cost issues, however, cannot be ignored which was the short coming of this study.

\section{References}

1. Ba F, Rieder HL (1999) A comparison of fluorescence microscopy with the Zeihl-Neelson technique in the examination of sputum for acid-fast bacilli. Int $\mathrm{J}$ Tuberc Lung Dis 3: 1101-1105.

2. Deshmukh SR, Mantri SB, Kendre PB, Nagoba BS (1996) A comparison of sputum examination for acid fast bacilli by modified Schaeffer and Fulton stain, Zeihl-Neelson stain and cold chain. Indian J Med Res 103: 294-295.

3. Kumar V, Abbas AK, Fausto N, Mitchell RN (2007) Robbins basic pathology. ( $8^{\text {th }}$ edn), Saunders Elsevier, Philadelphia.

4. Hooja S, Pal N, Malhotra B, Goyal S, Kumar V, et al. (2011) Comparison of Ziehl Neelsen \& Auramine O staining methods on direct and concentrated smears in clinical specimens. Indian J Tuberc 58: 72-76.

5. Golia S, Hittinahalli V, Nirmala AR, Sangeetha KT, Kamath BA (2013) A comparative study of Auramine staining using LED Fluorescent microscopy with Ziehl-Nelson staining in the diagnosis of pulmonary tuberculosis. J Evol Med Dent Sci 2: 3450-3456.

6. Kumar SJ, Chandrasekar C, Rajasekaran S (2012) Comparison of conventional and fluorescent staining methods in diagnosis of pulmonary tuberculosis among HIV seropositive individuals. J Evol Med Dent Sci 1: 463-466.

7. Ulukanligil M, Aslan G, Tasci S (2000) A comparative study on the different staining methods and number of specimens for the detection of acid fast bacilli. Mem Inst Oswaldo Cruz 95: 855-858.
8. Abdissa K, Tadesse M, Abdella K, Bekele A, Bezabih M, et al. (2015) Diagnostic performance of fluorescent lightemitting diode microscopy for tuberculous lymphadenitis in a high-burden setting. Trop Med Int Health 20: 1543-1548.

9. Desai K, Malek S, Mehtaliya C (2009) Comparative study of Z-N staining vs. fluorochrome stain from pulmonary and extrapulmonary tuberculosis. Gurajat Medical Journal 64: 32-34.

10. Murray SJ, Barrett A, Magee JG, Freeman R (2003) Optimisation of acid fast smears for the direct detection of mycobacteria in clinical samples. J Clin Pathol 56: 613-615.

11. Prasanthi K, Kumari A (2005) Efficacy of fluorochrome stain in the diagnosis of pulmonary tuberculosis co-infected with HIV. Indian J Med Microbiol 23: 179-181.

12. Jain A, Bhargava A, Agarwal S (2002) A comparative study of two commonly used staining techniques for acid fast bacilli in clinical specimens. Indian J Tuberc 49: 161-162.

13. Githui W, Kitui F, Juma ES, Obwana DO, Mwai J, (1993) A comparative study on the reliability of the fluorescence microscopy and Ziehl- Neelsen method in the diagnosis of pulmonary tuberculosis. East Afr Med J 70: 263-266.

14. Thakur B, Mehrotra R, Nigam J (2013) Correlation of various techniques in diagnosis of tuberculous lymphadenitis on fine needle aspiration cytology. Patholog Res Int 2013: 1-4.

15. Somoskovi A, Hataling JE, Fitzgerald M, O'Donnell D, Parsons LM, et al. (2001) Lessons from proficiency testing event for acid fast microscopy. Chest 120: 250-257.

16. Toman K (1979) Tuberculosis case finding and chemotheraphy. Questions and answers. ( $1^{\text {st }}$ edn), WHO, Geneva.

17. Gokhale S, Qadir S, Nagraj JS, AK Chakraborty (1990) Efficiency of cold staining method of AFB in sputum: A comparison of Ziehl-Neelsen method under field conditions. Int J Tub 37: 135.

18. Mistry Y, Rajdev S, Mullan S (2016) Comparative study of ZN staining vs. flurochrome staining and impact of sample processing on diagnosis of tuberculosis from various clinical samples. Advances in Microbiology 6: 953-958.

19. Dagar V, Heda S, Barsagade A, Mahore S, Ambhore N, et al. (2016) Comparision of ZN staining and fluorescent microscopy in detection of acid fast bacilli in fine needle aspiration smears. J Med Dent Sci 15: 79-84.

20. Zailani SB, Gabdo AH, Bukbuk DN (2012) Detection rates of Ziehl-Nelseen staining technique and fluoresecnt microscopy in the examination of sputum for acid fast bacilli. Bo Med J 9: 27-30.

21. Zaib-un-Nisa, Javed H, Zafar A, Qayyum A, Rehman A, et al. (2015) Comparison of fluorescence microscopy and Ziehl-Neelsen technique in diagnosis of tuberculosis in paediatric patients. J Pak Med Assoc 65: 879-881.

22. Subramani $P$, Venkteswarao $T$, Malligere Lingaiah $H$, Madappa B (2014) Evaluation of multiple laboratory methods in the diagnosis of extrapulmonary tuberculosis. Int J Med Pub Health 4: 482.

23. Smithwick RW (1976) Laboratory manual for acid-fast microscopy. US Public Health Service.

24. Tiwari VK, Gupta N, Bansal SA (2015) Comparative study of the diagnostic yield of fluorescent and Ziehl Neelsen staining techniques with the reference to the diagnosis of pulmonary tuberculosis. Int J Sci Res 251-252.

25. Marias BJ, Brittle W, Painczyk K, Hesseling AC, Beyers 
$\mathrm{N}$, et al. (2008) Use of light-emitting diode fluorescence microscopy to detect acid fast bacilli in sputum. Clin Infect Dis 47: 203-207.

26. Ramsay A, Cuevas L, Mundy C, Nathanson C, Chirambo $P$, et al. (2009) New policies, new technologies: Modelling the potential for improved smear microscopy services in Malawi. PLoS One 4: e7760.

27. Hänscheid T (2008) The future looks bright: Low-cost fluorescent microscopes for detection of Mycobacterium tuberculosis and coccidiae. Trans R Soc Trop Med Hyg 102: 520-521. 